\title{
Cardiorespiratory fitness and muscular strength of deaf futsal players
}

\author{
Eduardo Favretto', Willian Fin', José Carlos dos Santos Albarello', Gustavo Henrique Halmenschlager', Cleiton Chiamonti Bona', \\ Gilnei Lopes Pimentel', Leonardo Calegari ${ }^{2, *}$
}

'Biomechanics Laboratory, Faculty of Physical Education and Physiotherapy, University of Passo Fundo, Passo Fundo, Brazil

${ }^{2}$ Cardiopulmonary Laboratory, Faculty of Physical Education and Physiotherapy, University of Passo Fundo, Passo Fundo, Brazil

The present study compared the cardiopulmonary exercise capacity and peak torque of the knee extensor and flexor muscles in team players associated with the Gaucho Deaf Futsal Federation players to those of their hearing peers. In this cross-sectional study, 16 male athletes, eight futsal players with hearing impairment (deaf group, DG; $22.6 \pm 7.7$ years), and eight futsal players with normal hearing (control group, CG; $22.5 \pm 2.9$ years) underwent a cardiopulmonary test on a treadmill and isokinetic dynamometry at $60 \% \mathrm{sec}$. All athletes were subjected to a cardiopulmonary test on a treadmill and isokinetic dynamometry at $60^{\circ}$ sec. The main results showed a reduction in the cardiorespiratory fitness of deaf athletes when compared to the control group maximal oxygen consumption $\left(\mathrm{VO}_{2 \max }\right)(40.3 \pm 9.8 \mathrm{~mL} / \mathrm{kg} / \mathrm{min}$ vs. $50.7 \pm 4.7 \mathrm{~mL} / \mathrm{kg} / \mathrm{min}, P=$ $0.01)$, oxygen pulse $(15.3 \pm 4.8 \mathrm{~mL} / \mathrm{bpm}$ vs. $20.7 \pm 2.6 \mathrm{~mL} / \mathrm{bpm}, P=0.01)$ and ventilation $(70.1 \pm 22 \mathrm{~L} / \mathrm{min}$ vs. $96.2 \pm 15 \mathrm{~L} / \mathrm{min}, P=0.01)$, respectively. The relative torque peak of the dominant knee flexors was significantly lower in the deaf group when compared to the control $(1.5 \pm 0.2 \mathrm{~N} . \mathrm{m} / \mathrm{kg}$ vs. $1.9 \pm 0.2 \mathrm{~N} . \mathrm{m} / \mathrm{kg}, P=0.004$ ), respectively. There was a significant correlation between $\mathrm{VO}_{2 \max }$ and peak torque of the dominant knee flexors $\left(r_{\mathrm{s}}=0.83, P<0.001\right)$ and extensors $\left(r_{\mathrm{s}}=0.65, P=0.006\right)$. When compared to players with normal hearing, deaf players showed lower cardiorespiratory fitness and decreased knee flexor strength. The performance of the thigh muscles was associated with aerobic capacity.

Keywords: Oxygen consumption, Cardiopulmonary exercise test, Muscle strength, Deaf, Physical fitness, Futsal

\section{INTRODUCTION}

There is an estimation that 466 million people in the world have hearing-impairment (World Health Organization, 2018). Participation in team sports, such as futsal, improves the health and social lives of people with a hearing impairment (Palmer and Weber, 2006). Futsal is characterized as high-intensity exercise, an intermittent team game which have need high aerobic and anaerobic capacities (Galy et al., 2015) and no reports on oxygen uptake were found in the literature related to deaf futsal players. The rules of futsal for deaf people are the same as for regular futsal (Beato et al., 2016), except for the use of a flag to signal the infractions and all other events during the match.

Studies have shown that a hearing impairment is associated with low levels of physical activity in adolescents (Lobenius-Palmér et al., 2018), adults (Loprinzi et al., 2012) and in the elderly (Gispen et al., 2014). The lower adhesion of deaf people to physical exercise possibly due to the difference in language, which makes communication difficult between hearing and nonhearing people, may also influence cardiorespiratory capacity (Gispen et al., 2014; Loprinzi et al., 2012). Some authors have suggested that deaf people have lower cardiorespiratory fitness because the development of their lung volumes and capacities might be compromised due to the lack of stimuli such as speech, singing, or shouting (Żebrowska et al., 2007a; Żebrowska et al., 2007b).

The literature on the cardiorespiratory fitness of deaf individuals is still scarce. Some studies indirectly evaluated oxygen consumption $\left(\mathrm{VO}_{2}\right)$ through field tests and equations (Loprinzi et al.,
${ }^{*}$ Corresponding author: Leonardo Calegari (iD https://orcid.org/0000-0003-0758-3467 Faculty of Physical Education and Physiotherapy - University of Passo Fundo,

Campus 1 - BR 285, Bairro São José, Passo Fundo, RS 99052-900, Brazil E-mail: leocalegari@upf.br

Received: October 13, 2018 / Accepted: January 2, 2019
This is an Open Access article distributed under the terms of the Creative Commons Attribution Non-Commercial License (http://creativecommons.org/licenses/by-nc/4.0/) which permits unrestricted non-commercial use, distribution, and reproduction in any medium, provided the original work is properly cited. 
2012; Żebrowska et al., 2007a). Analysis of the ventilatory anaerobic threshold (VT) in futsal players allows us to evaluate the submaximal aerobic fitness and the physiological characteristics of each player (Alvarez et al., 2009). In addition, the evaluation of muscular strength using isokinetic dynamometry is important in the analysis of the performance of futsal players (de Lira et al., 2017); however, studies evaluating peak torque (PT) and total work $(\mathrm{J} / \mathrm{kg})$ of knee extensor and flexor muscles in deaf futsal players are rare in the literature. These analyses allow us to describe the profile of active deaf futsal players in Brazil.

Therefore, the present study aims to investigate whether hearing impairment affects cardiorespiratory fitness and PT of the knee extensor and flexor muscles in the players of a deaf team when compared to hearing futsal athletes. In addition, we investigated the relationship between isokinetic muscle performance and $\mathrm{VO}_{2}$.

\section{MATERIALS AND METHODS}

A cross-sectional study was performed by including 16 men, of which eight were hearing impaired athletes (deaf group, DG $\mathrm{n}=8$ and 22.6 \pm 7.7 years) and eight were professional futsal athletes with normal hearing (control group, $C G \mathrm{n}=8$ and $22.5 \pm 2.9$ years). The DG consisted of members of the second place team that played in the championship of the Regional Deaf Futsal Federation. All deaf athletes had hearing loss above $40 \mathrm{~dB}$. The CG consisted of athletes from different futsal teams from the bronze and silver series of Northern Rio Grande do Sul. Both group trained 2 to 3 times per week excluding matches. Goalkeepers were excluded from the analysis because they have a physical condition specific to the position. During all evaluations, a translator (LIBRAS Brazilian Sign Language) accompanied the deaf individuals, clarifying all the procedures.

After all orientations and clarifications, height and body mass were obtained using a anthropometric scale. The cardiopulmonary exercise test (CPET) was performed on treadmill using ramp protocol, with linear and progressive load increments until physical exhaustion and/or the onset of limiting signs and symptoms. During the test, the individuals were continuously monitored by three electrocardiographic leads, and the expired open circuit gases were analyzed (VO 2000 Software). Blood pressure (BP) and subjective quantification of Borg's perception of effort (6 to 20 points) were recorded at 3-min intervals. Anaerobic threshold was obtained by the ventilatory technique. The values found for VT and peak effort were calculated in averages of $40 \mathrm{sec}$. Respiratory exchange ratio (RER) $\geq 1.1$ was one of the criteria for terminating CPET (Deresz et al., 2018). Relative power was estimated from body weight, and the inclination and speed of the treadmill. Predicted $\mathrm{VO}_{2}$ was calculated using the equation: maximal $\mathrm{VO}_{2}\left(\mathrm{VO}_{2 \max }\right)=$ $53.478+(-7.518 \times$ gender $)+(-0.254 \times$ age $)+(-0.430 \times$ BMI $)+(6.132 \times$ physical activity), according to Almeida et al. (2014).

A computerized Biodex dynamometer Multi-Joint System 3 Pro model (Biodex Medical Systems, Inc., Shirley, NY, USA) was used for isokinetic evaluation. The protocol was initially reported to the interpreter, who in turn explained it in LIBRAS for the deaf athletes. Before the evaluation, the subjects warmed-up for $5 \mathrm{~min}$ on an electromagnetic bicycle without load (Movement Bm2700). Subsequently, the individuals were placed in the chair of the isokinetic equipment. The dynamometer chair was stabilized by restraint belts fixed on the trunk, hip, and thigh of the limb evaluated. The mechanical axis of rotation of the dynamometer was then aligned with the lateral epicondyle of the femur and the leg fixed to the arm of resistance of the dynamometer, $2 \mathrm{~cm}$ above the lateral malleolus, keeping the ankle joint free (Chiamonti Bona et al., 2017). Five submaximal repetitions were performed to familiarize the individuals with the equipment. The adopted protocol (Chiamonti Bona et al., 2017) consisted of five concentric/concentric repetitions for extension and flexion of the dominant knee at an angular velocity of $60^{\circ} / \mathrm{sec}$. The time interval between the CPET and the isokinetic evaluation was at least $48 \mathrm{hr}$.

This study was approved by the Research Ethics Committee at UPF under $\mathrm{n}^{\circ}$ 1.612.632 on June, 2016. All individuals agreed to participate in the research and signed a Consent Form. All procedures of investigation were conducted in accordance with CNS 466 resolution of December, 2012.

The data are presented as mean and standard deviation. The Kolmogorov-Smirnov test was used to analyze the normal distribution of the data. Comparisons between groups were analyzed by Student $t$-test for independent samples. Pearson correlation was used to analyze the association between $\mathrm{VO}_{2}$ and isokinetic muscle performance. Values of $P<0.05$ were considered significant.

\section{RESULTS}

The characteristics of the included players are described in Table 1 . The sample consisted of 16 individuals, eight deaf players and eight hearing players (control). Table 1 shows the anthropometric homogeneity between the groups.

Table 2 shows the values obtained in the CPET for both groups. $\mathrm{VO}_{2 \max }$, expressed in $\mathrm{mL} / \mathrm{min}$ (absolute value) or in $\mathrm{mL} / \mathrm{kg} / \mathrm{min}$ 
Table 1. Anthropometric characteristics of the sample

\begin{tabular}{lccccc}
\hline Variables & $\mathrm{DG}(\mathrm{n}=8)$ & $95 \% \mathrm{Cl}$ & $\mathrm{CG}(\mathrm{n}=8)$ & $95 \% \mathrm{Cl}$ & $P$-value \\
\hline Age $(\mathrm{yr})$ & $22.6 \pm 7.7$ & $16.2-29$ & $22.5 \pm 2.9$ & $20-24.9$ & 0.22 \\
Height $(\mathrm{cm})$ & $169 \pm 6$ & $164-173$ & $173 \pm 6$ & $168-177$ & 0.22 \\
Body mass $(\mathrm{kg})$ & $65.8 \pm 11.7$ & $56-75.5$ & $73.5 \pm 8.7$ & $66.2-80.7$ & 0.15 \\
\hline
\end{tabular}

Values are presented as mean \pm standard deviation unless otherwise indciated. $\mathrm{DG}$, deaf group; $\mathrm{CG}$, control group; $\mathrm{Cl}$, confidence interval.

Table 2. Cardiorespiratory variables obtained in the CPET in futsal players

\begin{tabular}{llcc}
\hline Variables & $\mathrm{DG}(\mathrm{n}=8)$ & $\mathrm{CG}(\mathrm{n}=8)$ & $P$-value \\
\hline HRmax $(\mathrm{bpm})$ & $179 \pm 7$ & $182 \pm 8$ & 0.39 \\
$\mathrm{HR} \mathrm{Rv}_{\text {v }}(\mathrm{bpm})$ & $150 \pm 13$ & $149 \pm 10$ & 0.87 \\
$\mathrm{VO}_{2 \max }(\mathrm{L} / \mathrm{min})$ & $2.72 \pm 0.8$ & $3.67 \pm 0.32$ & $0.01^{*}$ \\
$\mathrm{VO}_{2 \max }(\mathrm{mL} / \mathrm{kg} / \mathrm{min})$ & $40.3 \pm 9.8$ & $50.7 \pm 4.7$ & $0.01^{*}$ \\
$\mathrm{VO}_{2 \max }(\%$ of predicted$)$ & $82.4 \pm 18.5$ & $105.5 \pm 9.6$ & $0.01^{*}$ \\
$\mathrm{VO}_{2 \mathrm{VT}}(\mathrm{mL} / \mathrm{kg} / \mathrm{min})$ & $29.3 \pm 8.9$ & $36.17 \pm 5.4$ & 0.08 \\
$\% \mathrm{VO}_{2 \max }$ in VT & $72.7 \pm 12$ & $71.1 \pm 7.2$ & 0.76 \\
$\mathrm{VO}_{2} / \mathrm{HR}(\mathrm{mL} / \mathrm{bpm})$ & $15.3 \pm 4.8$ & $20.7 \pm 2.67$ & $0.01^{*}$ \\
$\mathrm{VE}(\mathrm{L} / \mathrm{min})$ & $70.1 \pm 22.3$ & $96.2 \pm 15$ & $0.01^{*}$ \\
$\mathrm{RER}$ & $1.16 \pm 0.05$ & $1.21 \pm 0.10$ & 0.12 \\
Relative power $(\mathrm{W} / \mathrm{kg})$ & $7.02 \pm 2.2$ & $8.29 \pm 1.16$ & 0.17 \\
\hline
\end{tabular}

Values are presented as mean \pm standard deviation.

CPET, cardiopulmonary exercise test; $\mathrm{DG}$, deaf group; $\mathrm{CG}$, control group; $\mathrm{HR}$, heart rate; HRmax, maximal $\mathrm{HR}$; $\mathrm{VO}_{2}$, oxygen consumption; $\mathrm{VO}_{2 \max }$, maximal $\mathrm{VO}_{2} ; \mathrm{VO}_{2} / \mathrm{FC}$, oxygen pulse; VE, expired volume/minute; VT, ventilatory threshold; RER, respiratory exchange rate.

$$
{ }^{*} P<0.05 \text {. }
$$

(relative value) were significantly lower in the DG when compared to the $\mathrm{CG}(P=0.01)$. The percentage of predicted $\mathrm{VO}_{2 \max }$ was significantly lower in the DG when compared to the $C G$ $(P=0.01)$. Oxygen pulse and expired minute volume were significantly lower in the DG when compared to the CG $(P=0.01)$. There were no significant differences in the other cardiopulmonary variables.

Table 3 shows the results obtained in isokinetic dynamometry for both groups. Absolute PT and total work of knee extensor and flexor muscle were significantly lower in the DG when compared to the CG $(P=0.01, P=0.001)$; and $(P=0.001)$, respectively. Moreover, we observed a decrease in the relative PT of the knee flexors in the DG $(P=0.004)$. There were no significant differences in PT corrected for body mass of the knee extensors.

Fig. 1 shows the correlations between $\mathrm{VO}_{2}$ obtained in the CPET and PT of dominant knee flexors (Fig. 1A) $\left(r_{s}=0.83, P<0.001\right)$ and extensors (Fig. 1B) $\left(r_{s}=0.65, P=0.006\right)$. Moreover, there were correlations between $\mathrm{VO}_{2}$ and total work corrected for body mass of dominant knee extensors (Fig. 1C) $\left(r_{\mathrm{s}}=0.65 ; P=0.005\right)$ on the isokinetic dynamometer at $60 \%$ sec.
Table 3. Isokinetic dynamometry of dominant knee flexors and extensors at $60^{\circ} / \mathrm{sec}$

\begin{tabular}{lccl}
\hline Variable & $\mathrm{DG}(\mathrm{n}=8)$ & $\mathrm{CG}(\mathrm{n}=8)$ & $P$-value \\
\hline Extensors absolute PT (N.m) & $204.8 \pm 30.7$ & $256.9 \pm 39$ & $0.01^{*}$ \\
Flexors absolute PT (N.m) & $98.3 \pm 14$ & $140.5 \pm 22.9$ & $0.001^{*}$ \\
Extensors relative PT (N.m/kg) & $3.1 \pm 0.4$ & $3.5 \pm 0.4$ & 0.08 \\
Flexors relative PT (N.m/kg) & $1.5 \pm 0.2$ & $1.9 \pm 0.2$ & $0.004^{*}$ \\
Extensors total work (J/kg) & $13.1 \pm 2.1$ & $17.8 \pm 2$ & $0.001^{*}$ \\
Flexors total work (J/kg) & $6.7 \pm 1.6$ & $10.5 \pm 2$ & $0.001^{*}$ \\
\hline
\end{tabular}

Values are presented as mean \pm standard deviation.

DG, deaf group; CG, control group; PT, peak torque.

Total work during 5 repetitions at an angular velocity of $60^{\circ} / \mathrm{sec}$.

${ }^{*} P<0.05$.
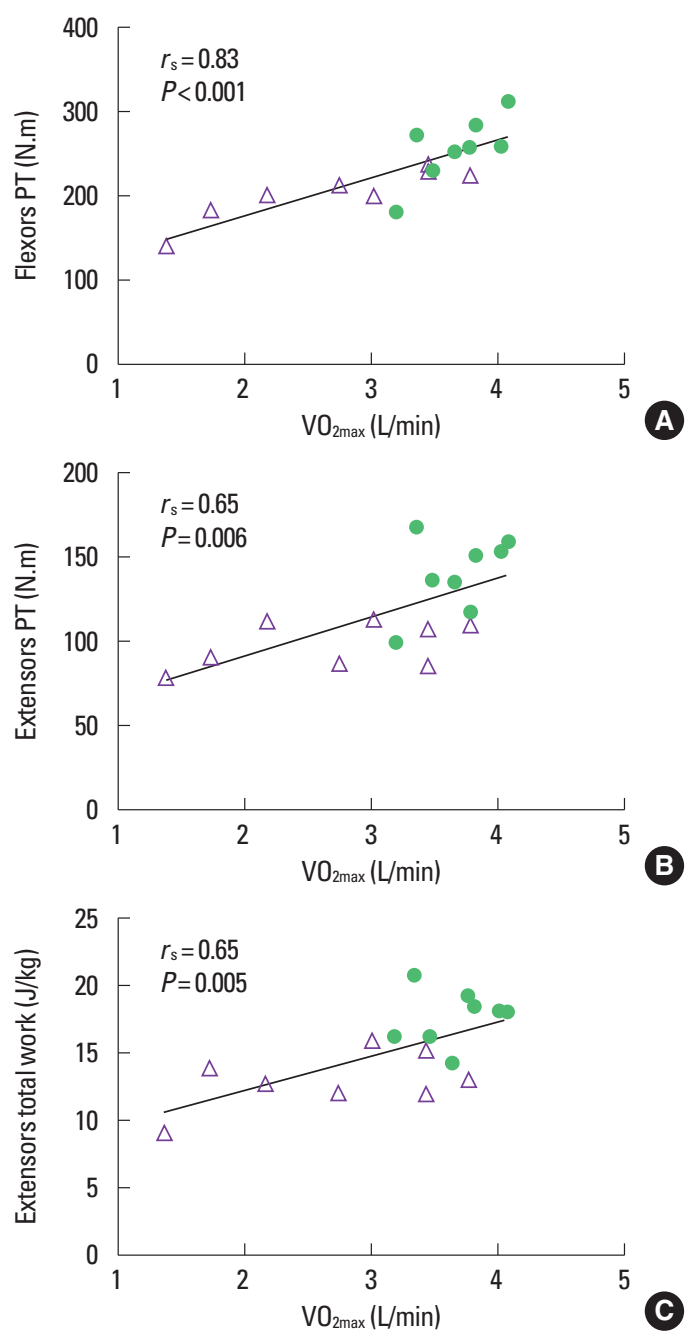

Fig. 1. Correlations between oxygen consumption obtained in the cardiopulmonary exercise test (CPET) and peak torque (PT) of dominant knee flexors. (A) Correlation between cardiorespiratory fitness (horizontal axis, maximal oxygen consumption $\left[\mathrm{VO}_{2 \max }\right]$ in $\mathrm{L} / \mathrm{min}$ ) and muscular performance (vertical axis, flexors PT in N.m). (B) Extensors PT. (C) Knee extensors total work $(\mathrm{J} / \mathrm{kg})$ in deaf futsal players (triangles) and controls (circle). 


\section{DISCUSSION}

This is the first study to show the cardiorespiratory and muscular strength characteristics of deaf futsal players. The main finding indicates a reduction in cardiorespiratory fitness and PT of the knee flexors of deaf athletes when compared to their hearing peers. Moreover, there was a significant correlation between PT of knee flexors and extensors with $\mathrm{VO}_{2 \max }$ suggesting that lower limb muscle strength is associated with athletes' aerobic performance.

The CPET with treadmill ramp protocol showed that $\mathrm{VO}_{2 \max }=$ $0.7 \pm 4.7 \mathrm{~mL} / \mathrm{kg} / \mathrm{min}$ for the hearing players. These values agree with those reported in Malaysian futsal players (Galy et al., 2015), $\mathrm{VO}_{2 \max }=51.4 \pm 3.2 \mathrm{~mL} / \mathrm{kg} / \mathrm{min}$, and in Brazilian professional futsal players (Floriano et al., 2016), $\mathrm{VO}_{2 \max }=49.6 \pm 4.7 \mathrm{~mL} / \mathrm{kg}$ / min. Our results, in addition to those found in the literature, provide a good benchmark for $\mathrm{VO}_{2}$ in futsal players, although some studies (Alvarez et al., 2009; Beato et al., 2016) have reported $\mathrm{VO}_{2 \max }$ closed to $60 \mathrm{~mL} / \mathrm{kg} / \mathrm{min}$. However, the group of deaf players obtained $\mathrm{VO}_{2 \max }$ of $40.3 \pm 9.8 \mathrm{~mL} / \mathrm{kg} / \mathrm{min},(82.4 \% \pm 18.5 \%$ of predicted) suggesting reduction in cardiorespiratory fitness. Previous studies support our findings, showing low $\mathrm{VO}_{2 \max }$ values in hearing-impaired female athletes (Ellis and Darby, 1993) and deaf adolescents (Żebrowska et al., 2007b). Hearing loss may impair motor development, possibly due to damage to the vestibular apparatus, causing physical consequences and dynamic balance deficiencies (Lévesque et al., 2014). It was reported that a deficiency in balance of hearing-impaired people may affect the $\mathrm{VO}_{2 \max }$ mainly in the treadmill test (Ellis and Darby, 1993). In addition, it is believed that prolonged periods of hearing loss may cause significant changes in sensory processing and motor deficits (Lévesque et al., 2014), which may influence maximal aerobic efficiency. Decreased gait speed and increased muscle activity were reported in children with hearing impairment, suggesting low gait efficiency (Majlesi et al., 2017). Recently, a study that evaluated the levels of physical activity with an accelerometer showed that younger deaf individuals are not physically active enough, which may influence their level of cardiorespiratory fitness (Lobenius-Palmér et al., 2018). Absolute and relative $\mathrm{VO}_{2 \max }$ decreased in deaf futsal players is likely multifactorial. $\mathrm{VO}_{2 \max }$ represents the integrative ability of the heart to generate a high cardiac output, total body haemoglobin, high muscle blood flow and muscle oxygen extraction, and in some cases the ability of the lungs to oxygenate the blood (Bassett and Howley, 2000). Furthermore, we observed lower oxygen pulse values $\left(\mathrm{VO}_{2} / \mathrm{HR}\right)$ in deaf futsal players when compared to their peers. Since the oxygen pulse consists of the volume of oxygen extracted by the peripheral metabolism with each heartbeat, deaf players seem to have lower stroke volume than control players for a given workload (Whipp et al., 1996) and similar results were found by Vujkov et al. (2010) in basketball players with hearing loss. It is possible that reduced stroke volume and/or diminished of arterio-venous oxygen content difference at maximal exercise might have been partly responsible by decreased of the $\mathrm{VO}_{2 \max }$ in the deaf players, whereas CPET provides a noninvasively estimate of stroke volume via $\mathrm{VO}_{2} / \mathrm{HR}$ (Van Iterson et al., 2018).

In addition, we observed lower peak exercise minute ventilation in deaf group. Spirometric evaluations of deaf adolescents suggest restrictive pattern related to lack of oral communication (Żebrowska et al., 2007a; Żebrowska et al., 2016). The maximal voluntary ventilation and forced vital capacity (\% pred) were lower in deaf adolescents compared with the hearing counterparts (Żebrowska et al., 2016). Although our study did not assess spirometric variables, deaf players showed a significantly reduction of $25 \mathrm{~L} / \mathrm{min}$ in peak VE when compared with hearing group, suggesting reduction on the compliance of lung and/or chest wall. Further studies are warranted to explore the pulmonary system during CPET in deaf players.

Evaluations at a submaximal intensity level, such as the ventilatory threshold (VT), did not show significant differences in the performance of deaf athletes when compared to their hearing peers. The percentage of $\mathrm{VO}_{2 \max }$ in the $\mathrm{VT}$ was $72.7 \% \pm 12 \%$ for the DG and $71.1 \% \pm 7.2 \%$ for the control group $(P=0.76)$, with relative power of $4.5 \pm 0.3 \mathrm{~W} / \mathrm{kg}$ and $4.6 \pm 0.3 \mathrm{~W} / \mathrm{kg}$ at VT $(P=0.84)$, respectively. Stress intensities higher than the VT could cause unpleasant sensations and reduced pleasure provided by exercise (da Silva et al., 2017).

Neuromuscular strength has been recognized as an important feature in intermittent sports, such as futsal (Nunes et al., 2018). The PT values of the extensors in the CG were $256 \pm 13 \mathrm{~N}$.m and of the flexors were $140 \pm 8 \mathrm{~N}$.m. To the best of our knowledge, no study so far has measured the PT in deaf futsal players. PT was evaluated in a group of deaf youths who participated in a traditional Greek dance program (Tsimaras et al., 2010), obtaining $187 \pm 68 \mathrm{~N}$.m for knee extensors, a value close to that obtained in the present study $204 \pm 10 \mathrm{~N} . \mathrm{m}$. Some authors argue that differences in performance between individuals with hearing loss and their hearing peers are related to external factors, previous motor experiences, and different movement learning abilities (Iwańska et al., 2013). After the standardization of PT by body weight, we did not find significant differences in PT of knee extensors be- 
tween the groups. We observed these values for this muscle group: $3.1 \pm 0.4 \mathrm{~N} . \mathrm{m} / \mathrm{kg}$ in the DG and $3.5 \pm 0.4 \mathrm{~N} . \mathrm{m} / \mathrm{kg}$ in the CG $(P=0.08)$ (Table 3). de Lira et al. (2017) found $3.1 \pm 0.3 \mathrm{~N} . \mathrm{m} / \mathrm{kg}$ for knee extensors in futsal players, supporting our results and suggesting that the muscular strength of the extensors is preserved in the deaf players (Szulc et al., 2017).

Our study found that higher absolute PT values of knee flexors and extensors are associated with higher $\mathrm{VO}_{2 \max }$ values. Moreover, we found a correlation with the total work of the knee extensors, which is the energy used for muscular effort during movement, i.e., the product of torque by angular displacement (Lee et al., 2017). In this context, the results of the total work corrected for body mass were significantly lower in deaf players, suggesting that lower values of total work may result in reduced cardiorespiratory fitness, measured by an incremental exercise test. Recently, the association between aerobic performance and total work was observed by other researchers (Lee et al., 2017). Furthermore, a significant relationship between functional tests and isokinetic muscle strength was found in soccer players and futsal players (de Lira et al., 2017).

Lobenius-Palmér et al. (2018) using an accelerometer showed that youngsters with disabilities spend only a small proportion of day in moderate-to-vigorous physical activity. The futsal had characteristics that induce moderate-to-vigorous-intensity of physical activity and we suggest futsal as a sport mode for inclusion of people with disabilities. In addition, many cities own indoor court where futsal could be played and this could promote physical activity decreasing the hurdles to disable sports.

The present study has some limitations that need to be considered. Regardless of the presence of a Libras interpreter during physical evaluations, the motivation and commitment of the deaf players might have been different from the hearing players. Isokinetic evaluations were performed at a single angular velocity $\left(60^{\circ} \%\right.$ $\mathrm{sec})$, other angular velocities could complement the results of muscle performance. The dynamic balance could be evaluated in deaf futsal players to avoid influence of the fear of falls on treadmill.

In conclusion, the deaf futsal players had a reduction in cardiorespiratory variables measured on treadmill. $\mathrm{VO}_{2}$, oxygen pulse, and minute ventilation were lower for the deaf group compared to their hearing peers. The relative torque peak of the knee flexors was lower in the deaf players, suggesting weakness of the hamstrings. There was an association between cardiorespiratory fitness and isokinetic performance of the thigh muscles, suggesting that strength training is a viable alternative to improve not only mus- cular performance but also the cardiorespiratory fitness of deaf players.

\section{CONFLICT OF INTEREST}

No potential conflict of interest relevant to this article was reported.

\section{REFERENCES}

Almeida AE, Stefani Cde M, Nascimento JA, Almeida NM, Santos Ada C, Ribeiro JP, Stein R. An equation for the prediction of oxygen consumption in a Brazilian population. Arq Bras Cardiol 2014;103:299-307.

Alvarez JC, D'Ottavio S, Vera JG, Castagna C. Aerobic fitness in futsal players of different competitive level. J Strength Cond Res 2009;23: 2163-2166.

Bassett DR Jr, Howley ET. Limiting factors for maximum oxygen uptake and determinants of endurance performance. Med Sci Sports Exerc 2000;32:70-84.

Beato M, Coratella G, Schena F. Brief review of the state of art in futsal. J Sports Med Phys Fitness 2016;56:428-432.

Chiamonti Bona C, Tourinho Filho H, Izquierdo M, Pires Ferraz RM, Marques MC. Peak torque and muscle balance in the knees of young U-15 and U-17 soccer athletes playing various tactical positions. J Sports Med Phys Fitness 2017;57:923-929.

da Silva WQA, Fontes EB, Forti RM, Lima ZL, Machado DGDS, Deslandes AC, Hussey E, Ward N, Mesquita RC, Okano AH, Elsangedy HM. Affect during incremental exercise: the role of inhibitory cognition, autonomic cardiac function, and cerebral oxygenation. PLoS One 2017; 12:e0186926.

de Lira CAB, Mascarin NC, Vargas VZ, Vancini RL, Andrade MS. Isokinetic knee muscle strength profile in Brazilian male soccer, futsal, and beach soccer players: a cross-sectional study. Int J Sports Phys Ther 2017;12:1103-1110.

Deresz LF, Karsten M, Corrêa IF, Sonza A, Ikeda MLR, da Silva CS, Lago PD. Functional capacity and ventilatory efficiency are preserved in well-controlled people living with human immunodeficiency virus/ acquired immunodeficiency syndrome. J Exerc Rehabil 2018;14:680687.

Ellis MK, Darby LA. The effect of balance on the determination of peak oxygen consumption for hearing and nonhearing female athletes. Adapt Phys Act Q 1993;10:216-225.

Floriano LT, da Silva JF, Teixeira AS, Salvador PC, Dittrich N, Carminatti LJ, Nascimento LL, Guglielmo LG. Physiological responses during the time limit at $100 \%$ of the peak velocity in the Carminatti's test in 
futsal players. J Hum Kinet 2016;54:91-101.

Galy O, Zongo P, Chamari K, Chaouachi A, Michalak E, Dellal A, Castagna $\mathrm{C}$, Hue O. Anthropometric and physiological characteristics of Melanesian futsal players: a first approach to talent identification in Oceania. Biol Sport 2015;32:135-141.

Gispen FE, Chen DS, Genther DJ, Lin FR. Association between hearing impairment and lower levels of physical activity in older adults. J Am Geriatr Soc 2014;62:1427-1433.

Iwańska D, Madej A, Urbanik C. Comparative analysis of endurance of not hearing and hearing students. Biomed Hum Kinet 2013;5:51-58.

Lee CB, Eun D, Kim KH, Park JW, Jee YS. Relationship between cardiopulmonary responses and isokinetic moments: the optimal angular velocity for muscular endurance. J Exerc Rehabil 2017;13:185-193.

Lévesque J, Théoret H, Champoux F. Reduced procedural motor learning in deaf individuals. Front Hum Neurosci 2014;8:343.

Lobenius-Palmér K, Sjöqvist B, Hurtig-Wennlöf A, Lundqvist LO. Accelerometer-assessed physical activity and sedentary time in youth with disabilities. Adapt Phys Activ Q 2018;35:1-19.

Loprinzi PD, Cardinal BJ, Gilham B. Association between cardiorespiratory fitness and hearing sensitivity. Am J Audiol 2012;21:33-40.

Majlesi M, Azadian E, Farahpour N, Jafarnezhad AA, Rashedi H. Lower limb muscle activity during gait in individuals with hearing loss. Australas Phys Eng Sci Med 2017;40:659-665.

Nunes RF, Dellagrana RA, Nakamura FY, Buzzachera CF, Almeida FAM,

Flores LJF, Guglielmo LGA, da Silva SG. Isokinetic assessment of muscular strength and balance in Brazilian elite futsal players. Int J Sports Phys Ther 2018;13:94-103.

Palmer T, Weber KM. The deaf athlete. Curr Sports Med Rep 2006;5:323326.

Szulc AM, Buśko K, Sandurska E, Kołodziejczyk M. The biomechanical characteristics of elite deaf and hearing female soccer players: comparative analysis. Acta Bioeng Biomech 2017;19:127-133.

Tsimaras VK, Kyriazis DA, Christoulas KI, Fotiadou EG, Kokaridas DG, Angelopoulou NA. The effect of a traditional dance training program on the physical fitness of adults with hearing loss. J Strength Cond Res 2010;24:1052-1058.

Van Iterson EH, Baker SE, Wheatley CM, Morgan WJ, Olson TP, Snyder EM. Exercise stroke volume in adult cystic fibrosis: a comparison of acetylene pulmonary uptake and oxygen pulse. Clin Med Insights Circ Respir Pulm Med 2018;12:1179548418790564.

Vujkov S, Đukic M, Drid P. Aerobic capacity of handball players with hearing impairment. Biomed Hum Kinet 2010;2:58-61.

Whipp BJ, Higgenbotham MB, Cobb FC. Estimating exercise stroke volume from asymptotic oxygen pulse in humans. J Appl Physiol (1985) 1996;81:2674-2679.

World Health Organization. Deafness and hearing impairment. [Internet]. Genève (Switzerland): World Health Organization; 2018 [cited 2018 Jul 1] Available from: http://www.who.int/mediacentre/factsheets/ fs300/en/.

Żebrowska A, Gawlik K, Zwierzchowska A. Spirometric measurements and physical efficiency in children and adolescents with hearing and visual impairments. J Physiol Pharmacol 2007a;58 Suppl 5(Pt 2):847857.

Żebrowska A, Zwierzchowska A, Gawlik K. The dynamics of maximal aerobic efficiency in children and adolescents with hearing and visual impairment. J Hum Kinet 2007b;17:53-62.

Żebrowska A, Zwierzchowska A, Manowska B, Przybyła K, Krużyńska A, Jastrzębski D. Respiratory function and language abilities of profoundly deaf adolescents with and without cochlear implants. Adv Exp Med Biol 2016;912:73-81. 